\title{
Commentary Wireless technology in the ICU: boon or ban?
} Aviv S Gladman ${ }^{1}$ and Stephen E Lapinsky ${ }^{1,2}$

\author{
${ }^{1}$ Interdepartmental Division of Critical Care Medicine, University of Toronto, Canada \\ 2Intensive Care Unit, Mount Sinai Hospital, Toronto, Canada
}

Corresponding author: Stephen E Lapinsky, Stephen.lapinsky@utoronto.ca

Published: 11 September 2007

Critical Care 2007, 11:165 (doi:10.1186/cc6112)

This article is online at http://ccforum.com/content/11/5/165

(C) 2007 BioMed Central Ltd

See related research by van Lieshout et al., http://ccforum.com/content/11/5/R98

\begin{abstract}
Wireless communication and data transmission are playing an increasing role in the critical care environment. Early anecdotal reports of electromagnetic interference (EMI) with intensive care unit (ICU) equipment resulted in many institutions banning these devices. An increasing literature database has more clearly defined the risks of EMI. Restrictions to the use of mobile devices are being lifted, and it has been suggested that the benefits of improved communication may outweigh the small risks. However, increased use of cellular phones and ever changing communication technologies require ongoing vigilance by healthcare device manufacturers, hospitals and device users, to prevent potentially hazardous events due to EMI.
\end{abstract}

The numerous anecdotal reports of catastrophic medical equipment failure in close proximity to electromagnetic field emitters (such as mobile phones or other wireless devices) have recently been supported by formal studies. Van Lieshout et al. add to this growing literature database by reporting the effects of electromagnetic interference (EMI) produced by newer generation mobile phone signals on medical devices commonly used in an intensive care unit (ICU) [1]. Based on a high $(43 \%)$ rate of EMl-related incidents at a median distance of $3 \mathrm{~cm}$, they reasonably conclude that mobile phone use in critical care units should be restricted to the usual $1 \mathrm{~m}$ distance from the critical care bedside [2]. These investigators used a worst case scenario in their study design, simulating electromagnetic (EM) fields at the maximum signal strength generated by mobile phones and intentionally targeting poorly shielded locations on the tested medical devices. The high rate of hazardous incidents that they found may not represent what would be expected from routine mobile phone use. Other studies reporting on the susceptibility of commercial medical devices to EMI in real life (as opposed to laboratory) environments using reasonable distance restrictions have found fewer clinically relevant EMI events [3-5]. Although van Leishout's data can be interpreted as supportive of the use of mobile phones - $94 \%$ of hazardous events occurred at a distance of $30 \mathrm{~cm}$ or less the danger of relying on a $1 \mathrm{~m}$ restriction is highlighted. The catastrophic failure of a ventilator at a distance of $3 \mathrm{~m}$ from a mobile phone signal raises serious concerns about industrial standards, as the authors note in their conclusions.

Industrial standards for life-supporting medical devices (International Electrotechnical Commission [IEC] Standard 60060-1-2) fall substantially short of achievable standards for example, for military equipment (MIL-STD-461). Almost a decade ago, the Institute of Electrical and Electronics Engineers (IEEE) Committee on Man and Radiation noted that technology existed to protect most medical devices from radiofrequency fields much more intense than the IEC standards, and that shielding, grounding and filtering, were not costly when incorporated into the initial device design [6]. Despite that, and in the face of growing evidence of EMI in the literature, there have been no substantial changes to EMI susceptibility standards for medical devices in the last decade. Newer generation wireless devices are rapidly expanding into frequency spectrums not covered by current standards for medical devices, necessitating more frequent reevaluation of those standards. Hospitals rely on manufacturers' stipulated adherence to EMI standards, typically based on third-party susceptibility testing of a small number of sample devices. Electromagnetic susceptibility of an individual medical device may vary due to poor quality control during construction. Compliance with standards cannot be guaranteed, which may explain why some devices fall below the Food and Drug Administration (FDA) standard when tested in hospital environments.

$\mathrm{EMI}=$ electromagnetic interference; $\mathrm{EM}=$ electromagnetic; FDA = Food and Drug Administration; ICU = intensive care unit; IEC = International Electrotechnical Commission ; IEEE = Institute of Electrical and Electronics Engineers. 
Regardless of the potential risks, wireless technology is becoming increasingly prevalent in the critical care environment. Hospitals are routinely using wireless solutions for patient monitoring, data collection, and enhanced communication. Several companies are now offering wireless solutions for electronic-ICU applications, using either their own proprietary networks, or 'piggybacking' on existing hospital networks. A new generation of transport monitors and external defibrillators offers wireless transmission to hospital telemetry systems. Current data suggest that wireless area networks (802.11) and Bluetooth systems do not carry a risk of EMI with medical devices [7,8]. However, the rapid development of new wireless telecommunication technologies makes much of the current literature obsolete. With each new generation of wireless technology, information technologists and medical engineers must determine the impact on existing hospital network infrastructure and medical devices.

There are those that argue that the intangible benefits of improved communication using wireless devices far outweigh the small risk of a hazardous event from EMI [9]. As wireless devices become less expensive and consequently more prevalent we are also seeing increasing use of data transmission (email, web access) in addition to voice communication, by staff and visitors. Increased awareness of the risks of EMI, by staff, patients and visitors, is essential to ensure sensible use of wireless devices. There are other aspects of electromagnetic interference that may need to be considered, such as bandwidth competition by medical devices employing the same local wireless networks, or between medical devices and personal wireless products. As restrictions on the use of wireless technology are relaxed, increased vigilance and testing of new wireless devices and their transmission networks is essential, in our own hospital environments with our own equipment.

\section{Competing interests}

The author(s) declare that they have no competing interests.

\section{References}

1. van Lieshout, JE, van der Veer SN, Hensbroek R, Korevaar JC, Vroom MB, Schultz MJ: Interference by new generations mobile phones on critical care medical equipment. Critical Care 2007, 11:R98.

2. Lapinsky SE, Easty AC: Electromagnetic interference in critical care. J Crit Care 2006, 21:267-270.

3. Tan K-S, Hunberg I, Wadhwani J: Electromagnetic interference in medical devices. Medical Electronics Manufacturing 2001, Fall. Available at: http://www.devicelink.com/mem/archive/01/09/ 010.html (accessed Sept 6, 2007)

4. Tri JL, Severson RP, Hyberger LK, Hayes DL: Use of cellular telephones in the hospital environment. Mayo Clin Proc 2007, 82:282-5

5. Wallin MK, Marve T, Hakansson PK: Modern wireless telecommunication technologies and their electromagnetic compatibility with life-supporting equipment. Anesth Analg 2005, 101: 1393-400.

6. Committee on Man and Radiation (COMAR) Reports: Radiofrequency interference with medical devices: a technical information statement. IEEE Eng Med Biol Mag 1998, 17:111-114.
7. Tan KS, Hinberg I: Effects of a wireless local area network (LAN) system, a telemetry system, and electrosurgical devices on medical devices in a hospital environment. Biomed Instrum Technol 2000, 34:115-8.

8. Wallin MK, Wajntraub S: Evaluation of Bluetooth as a replacement for cables in intensive care and surgery. Anesth Analg 2004, 98:763-7

9. Soto RG, Chu LF, Goldman JM, Rampil IJ, Ruskin KJ: Communication in critical care environments: mobile telephones improve patient care. Anesth Analg 2006, 102:535-41. 